\title{
Participation of Elementary School Girl's Sports Club and Activation Plan of Elementary School Girls' Participation in P.E.
}

\author{
Min Young Park, Woo Seop Eom* \\ Seoul National University of Education, Seoul, Korea
}

\begin{abstract}
Received: October 10, 2017

Accepted: February 28, 2018

Published online: April 30, 2018

Keywords:

Elementary P.E

Female Students P.E

Sports Club

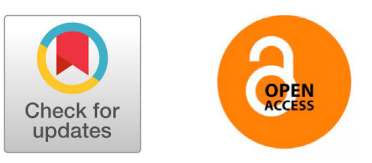

PURPOSE The purpose of this study is to propose a plan to revitalize the physical education classes for girls based on the sport club activity.

METHODS A qualitative study was conducted on 7 female students participated in sports club and P.E class. Data were collected through in-depth interviews, participation observation, and teaching essay. The collected data were subjected to writing, coding, and subject discovery processes.

RESULTS First, elementary school girls participating in sports clubs are follow friends or sports, start to love it, I want to win but I am trembling and scared. Second, elementary school girls participation factors in sports club is our own azit, cooperative participation of boys, and time without criticism. Third, based on the participation factors of sports clubs, the sports education model was proposed as a way to activate the participation in the physical education class for girls. And the sports education model should include season operation, student-centered participation, festival for all students.

CONCLUSIONS Elementary school girl's participation in sports club starts with following friends, interests in sports and goes to attachment and desire to win, fear. And girl's sports club need their own azit, cooperative participation of boys, activity time with criticism. These suggest that sports education model could be one of the solutions for activating girls participation in P.E
\end{abstract}

( ) The Asian Society of Kinesiology and the Korean Academy of Kinesiology
서론

초등교육에서의 체육교과의 방향과 역할은 신체활동 을 통하여 체력 및 운동 능력을 기르고 자신과 세계를 이 해하며 바람직한 품성과 사회성을 갖추어, 건강하고 활 기찬 삶에 필요한 능력과 함께 체육 문화를 창조적으로 계승/발전시킬 수 있는 자질을 함양하는 것이다(SMOE, 2011). 이렇게 신체 활동을 매개로 한 체육교과에 대한 초 등학생들의 선호도는 매우 높다. 신체적 발달 단계 상 충 만한 초등학교 학생들의 움직임 욕구를 충족시켜주는 것

*Correspondence: Woo Seop Eom, Seoul National University Of Education, 96, Seochojungang-ro, Seocho-gu, Seoul, Korea.

E-mail: ews@snue.ac.kr
외에도 인지적, 정의적 영역에서의 발달에 고르게 영향을 끼치는 부분이 있기 때문이다.

그런 데 이렇게 초등학생들의 전인적 성장을 돕는 부분 은 차치하고서라도, 분명하게 드러나는 체육교과의 명확 한 장점이 있다. 교과 선호도에 관한 질문에서 체육이 1,2 위를 놓치지 않는 이유에서 알 수 있는 과목에 대한 흥미 도가 그것이다. 운동장에서, 체육관에서, 그리고 또 무용 실에서 다른 교과와 다르게 신체를 마음껏 움직이면서 활 동할 수 있는 체육교과의 특성이 학생들로 하여금 끊임없 이 기대를 불러일으키며 흥미를 가지게 하는 것이다.

그러나 이러한 체육교과에 대한 학생들의 높은 흥미도 와 활발한 참여에도 불구하고, 학년이 올라갈수록 체육수 업을 기피하는 초등학생들도 늘어가고 있다. 특히 여학생 의 경우에 그런 경향을 보이는 일이 많은데, 남학생들에

(1) This is an open-access article distributed under the terms of the Creative Commons Attribution License (http://creativecommons.org/licenses/by-nc/4.0/), which permits unrestricted use, distribution, and reproduction in any medium, provided the original work is properly cited.

14 | The Asian Journal of Kinesiology 
비해 다소 부족한 운동 기능으로 인해 수업에 대한 흥미 마저 저하되는 경우(Bae et al. 2005)를 비롯하여 정규 교육 과정을 충실히 따르기 보다는 공 던져주고 자유 시간을 주거나(아나공 수업) 기후 및 수업 환경의 영향에 따른 참 여의 어려움(Yang, 2003) 같은 요인들 때문이다.

이처럼 여학생의 체육수업 기피 경향은 이미 상당한 수준이 이르렀다고 할 수 있다. 해외 연구에서도 수업에 참여하지 않는 여학생 비율이 $14 \%$ 에 이르거나(Williams \& Gill, 1995), 중학교에 올라간 여학생의 체육 수업에 대한 인식 및 참여 경험이 남학생보다 부정적이며, 자신감 또 한 적게 나타나는 사례 등이 보고되고 있다(Greendorfer, 1992; Walling \& Martinek, 1995).

여학생의 체육수업을 기피하는 경향이 심해지는 현상 은 남성 중심적인 체육 문화와사회적으로 형성된 심리적 영향 때문이기도 하다(Casey, Eime, Payne \& Harvey, 2009; Dwyer, Allison, Goldenberg, Fein, Yoshida \& Boutilier, 2006; Shen, Rinehart Lee, Mc Caughtry \& Li, 2012). 이는 단순히 과 목에 대한 흥미도 문제를 넘어 학생들의 건강 측면에서 큰 문제가 될 수 있다. 기초 체력 향상을 통한 건강 증진에 큰 역할을 하는 것이 평생체육이며, 한 사람의 삶에서 평 생체육의 기틀을 다져가는 단계는 바로 학교체육이다. 평 생체육의 습관화를 위해서라도 초등학교 단계에서 여학 생들에 게 생겨나는 체육 수업에 대한 부정적 인식을 경감 시키는 것이 매우 중요하며, 이는 학교체육이 꼭 해결해 야 할 과제이다(Robert \& Steven, 2002; Yoo, 2004).

이러한 과제를 앞에 두고, 국가적 차원에서 학생들의 신체활동을 장려하고 평생체육의 기틀을 다지기 위해 지 난 2007년부터 학교스포츠클럽 제도를 기획하여 운영하 고 있다. 올해로 운영한 지 10 년째가 되는 학교스포츠클 럽 제도는, 양적으로 빠르게 성장하여 서울특별시 기준 2008 년도 2 개의 시범 종목이 2016년 13 개의 지정종목으로 확대되어. 전국 규모의 학교스포츠클럽 대회가 매년 열리 고 있다(SMOE, 2016).

학교스포츠클럽은 교내에서 실시되는 교육활동으로 학교 시설을 그대로 이용할 수 있고, 교내에 많은 학생을 자연스럽게 참여할 수 있도록 유도할 수 있다는 점에서 여학생 체육 활성화를 도모할 수 있는 효율적인 방법이라 고 할 수 있다(CDC, 2002).

이에 더하여 학교스포츠클럽 참여에 관한 질적 성장을 도모하기 위하여 학교스포츠클럽 제도 내에 인성실천클 럽과 여학생 스포츠클럽 사업을 추가로 진행하고 있는데
특히 여학생 스포츠클럽 사업은 일반 스포츠클럽보다 더 많은 예산을 지원하며 활동을 장려함으로써 여학생들의 신체활동 활성화를 도모하고 있다. 이러한 여학생스포츠 클럽에 참여하는 여학생들은 남학생 없이 여학생만 모여 신체활동에 참여하는, 정과체육시간에 느껴보지 못한 경 험을 습득하고 있다.

그러나 여학생스포츠클럽 참여사례에 대한 연구는 많 이 다루어지지 않고 있으며, 대부분의 연구들이 중학교 여학생을 대상으로 하고 있다(Youn, 2013; Oh, 2015; Kang, 2016;). 최근 스포츠클럽 참여에 따른 초등학교 여학생의 체육에 대한 인식 변화 연구(Kim \& Kim, 2017;) 등이 이루 어지고 있으나, 여학생 스포츠클럽을 통한 체육활동 활성 화 방안은 연구동향 분석 정도의 연구(Kim, 2017;) 외에는 이루어지지 않고 있다. 여학생 체육 프로그램의 실효성과 타당성을 검증하고 있는 외국의 사례(Birgitta Fagrell,; Hakan Larsson \& Karin Redelius, 2012; Tylor, Hughes \& Koufaki, 2013)와 같이 여학생 스포츠클럽에 대한 적합성을 평가하 고, 스포츠클럽 참여의 긍정적인 요소를 체육수업으로 연 계하는 것과 관련된 연구 또한 필요한 부분이다.

이에 본 연구에서는 초등학교 여학생의 스포츠클럽참 여 모습을 관찰하여 참여 요인을 밝히고, 이와 연계한 여 학생 체육수업 참여 활성화 방안을 제시하고자 한다.

\section{연구 방법}

\section{연구대상}

본 연구의 연구자는 A교육대학교를 졸업하고 서울 소 재 평등초등학교에 재직 중인 교육경력 4 년차의 교사로, 지난 2년간의 교과전담교사 기간 동안 체육교과 지도 및 다수의 교내 스포츠클럽을 지도하였다.

본 연구의 배경이 되고 있는 A초등학교 학교스포츠클 럽(여자배구팀)을 지도한 것은 교육대학교 재학 시절 배 구 동아리를 통해 학부 시절동안 배구부 활동에 참여하는 것이 계기가 되었으며, 졸업 후 현장교사가 된 이후에도 사회인 배구대회에 출전하면서 선수와 지도자로서 끊임 없이 배구에 대한 소양을 쌓아가고 있다.

본 연구의 참여자는 연구자가 지도하고 있는 $\mathrm{A}$ 초등 학교 학교스포츠클럽(여자배구팀) 참가학생 20명 중에 서 연구자의 주관적 판단에 의한 목적 표집법(purposeful sampling)에 의해 7명을 선정하였다.

먼저 운동기능에 따라 체육수업 체험 경험이 현저히 


\begin{tabular}{|c|c|c|c|c|}
\hline Name & Class & Group & $\begin{array}{l}\text { PAPS } \\
\text { Grade }\end{array}$ & Note \\
\hline Ji-sun & 1 & A & 1 & leader, excellent sports skills \\
\hline Ha-neul & 1 & A & 2 & $\begin{array}{l}\text { second leader, strong desire } \\
\text { to win }\end{array}$ \\
\hline Hwan-hee & 1 & A & 3 & first apply, invite friends \\
\hline Jin-sun & 1 & A & 1 & $\begin{array}{l}\text { late apply, excellent sports } \\
\text { skills }\end{array}$ \\
\hline Ha-nee & 2 & B & 2 & $\begin{array}{l}\text { second leader, managing } \\
\text { conflict }\end{array}$ \\
\hline Sun-young & 2 & B & 3 & apply after cheering match \\
\hline So-jin & 2 & B & 2 & $\begin{array}{l}\text { strong self-expression, } \\
\text { conflict with others }\end{array}$ \\
\hline
\end{tabular}

달라진다는 점(Portman, 1992; Kim, 2003)을 고려하여, 객 관적인 운동기능의 지표인 학생건강체력평가(PAPS) 등 급별로 고르게 연구 참여자 후보를 선정하여 다양한 체험 형태를 살펴볼 수 있도록 하였다. 그리고 이들 중 연구자 와2년 동안 체육을 비롯한 여러 교과 수업을 함께 함으로 써 래포가 잘 형성되어 있고, 이를 통해 자신의 내면을 드 러내는 자연스러운 의사소통이 이루어질 거라 기대되는 7 명을 연구 참여자로 최종 결정하였다.

의사 표현 능력이 다소 부족한 초등학생의 특징을 고 려하여 편안한 분위기에서 스스럼없이 자기 자신을 드러 낼 수 있도록 학교에서 대부분의 시간을 함께 보내는 같 은 반 학생들을 같은 그룹으로 하여 2개 그룹으로 나누었 으며, 그룹별 면담 및 1:1 면담 방식을 활용하여 심층 면담 을 실시하였다. 심층 면담을 비롯한 자료 수집에 앞서서 연구의 취지를 상세히 설명하였고, 참가 의사를 확인하였 으며 개인정보 보호를 위해 가명을 사용하였다. 연구 참 여자에 대한 대략적인 정보는 < Table 1>과 같다.

\section{자료수집}

본 연구의 자료를 위해 연구자는 2016년 4월 여자배구 팀을 조직하고 직접 운영하면서 연구 참여자들을 선정하 였다. 수집한 자료는 연구 참여자와의 심층 면담 자료와 연구자의 참여 관찰 자료 및 지도 일지이다.

심층 면담은 자기표현 능력이 미숙한 초등학생임을 고 려하여 사전에 만든 질문지에 따라 순서대로 질문하되, 중간 중간에 추가 질문을 제시하는 반구조화 면담 방법을 이용하였다. 그룹 면담은 (1)스포츠클럽 시작 (2)스포츠클
럽 토너먼트 출전 (3)정과체육 간이배구 리그 진행의 3 가 지 주요 스케줄이 끝날 때마다 1회씩 총 3회 실시하였으 며, 그룹면담 이후에 2학기에 필요에 따라 개인 면담을 일 부 연구 참여자에 대해 실시하였다. 반구조화 면담 질문 지는 아래<Table 2>과 같다.

참여관찰은 연구자가 연구 참여자들이 소속된 집단에 직접 참여하면서 그들의 의사소통과 행동을 비롯하여 연 구자 자신의 경험을 자료로써 수집하는 방법이다(Kim, 2012). 본 연구자는 연구 참여자들이 소속된 여자배구팀 을 지도하여, 대회에 인솔하고 체육수업시간에 관찰한 연 구 참여자들의 행동들을 기록, 자료로 활용하였다.

지도일지는 연구자가 여자배구팀 지도시간 및 체육수 업 시간에 간이 배구를 지도하면서 연구자 자신의 인식 변화나 느낌 및 의미 있는 사건과 그에 대한 고찰을 기록 해놓은 일지를 의미한다. 주로 훈련 지도와 수업에 대한 반성적 접근을 통한 기록이 대부분이다.

\section{자료분석}

반구조화 면담을 바탕으로 수집한 심층 면담 자료는, 면담 내용을 MP3로 녹음 후 워드프로세서를 이용하여 문 서 파일로 전사하여 자료로 이용하였다. 참여 관찰 일지 및 지도 일지는 또한 워드프로세서로 문서화하여 자료화 하였다.

자료 분석은 전사, 코딩(주제별 약호화), 주제 발견의 3 단계를 거치는 귀납적 범주 분석을 실시하였다(Creswell,

\begin{tabular}{|c|c|}
\hline \multicolumn{2}{|r|}{ Main Question } \\
\hline $\begin{array}{l}1^{\text {st }} \\
\text { group } \\
\text { interview }\end{array}$ & $\begin{array}{l}\text { Sportsclub Start [April. 2016-May. 2016] } \\
\text { - Why are you apply volleyball team? } \\
\text { - What do you like the most in our volleyball activity? } \\
\text { - How do you think about volleyball? }\end{array}$ \\
\hline $\begin{array}{l}2^{\text {nd }} \\
\text { group } \\
\text { interview }\end{array}$ & $\begin{array}{l}\text { Sportsclub Tournament [May. 2016-June. 2016] } \\
\text { - How do you feel about sportsclub tournament? } \\
\text { - How's your change after sportsclub tournament? } \\
\text { - How's the relationship change after sportsclub } \\
\text { tournament? }\end{array}$ \\
\hline $\begin{array}{l}3^{\text {rd }} \\
\text { group } \\
\text { interview }\end{array}$ & $\begin{array}{l}\text { Simple-volleyball League in P.E [July. 2016-SEP. 2016] } \\
\text { - Think about simple-volleyball league in P.E } \\
\text { - Impression about simple-volleyball league in P.E } \\
\text { - How's the volleyball training with boys? }\end{array}$ \\
\hline $\begin{array}{l}\text { Personal } \\
\text { Interview }\end{array}$ & $\begin{array}{l}2^{\text {nd }} \text { Semester [July. 2016-SEP. 2016] } \\
\text { - Think about your sports skills } \\
\text { - Relationship with some teammates } \\
\text { - Ongoing participation after simple-volleyball league }\end{array}$ \\
\hline
\end{tabular}


2009). 먼저 수집된 자료들을 전사한 후 반복하여 읽으면 서 의미 있는 부분을 스크랩하여 모으는 코딩 과정을 거 친 후, 여학생 스포츠클럽 참여와 체육활동 활성화와 연 계된 주제를 도출하였다.

아울러 자료의 진실성을 확보하기 위하여 연구 참여자 에게 수집된 자료의 진위 여부를 확인하게 하였으며, 코 딩과 관련된 자료 분석 및 주제 도출과 관련된 자료 해석 단계에서 질적 연구 전문가인 교수 1 인과 박사과정 1 인의 검토를 통해 연구의 신뢰도를 확보하기 위해 노력하였다.

그리고 질적 연구에서 발생할 수 있는 윤리적인 문제 를 고려하여 본 연구에서는 다음과 같은 사항을 고려하였 다. 먼저 연구 참여자의 동의를 구하여 연구 참여자를 선 정하였으며, 자료수집 시간 및 자료 수집 장소 또한 연구 참여자가 선택하게 하였다. 연구 참여자들의 개인 정보를 보호하기 위해 가명을 사용하는 한편 자료가 유출되지 않 도록 노력하였으며 연구 참여자들에게 연구목적을 명확 하게 전달하여 오해의 소지가 없도록 하였다.

\section{결과}

\section{스포츠클럽 활동 참여 모습}

친구 따라 혹은 운동 쫓아 연구자 : "6학년에 들어와서 내가 체육수업을 맡게 되고, 너희들에게 스포츠클럽 여자배구팀이 생긴다고 홍보를 했었지. 사실 모집하 는 기간 초기에는 환희를 제외하고 찾아오는 사람이 없었는데 어떻게 가입하게 되었니?"

환희 : "전 5학년 때 코프볼 스포츠클럽에 지원했다가 선발 시험에서 떨어졌었거든요. 올해도 코프볼과 배구 두 클럽이 있다고 하는데, 코프볼은 또 떨어질까 봐 두려웠 고 배구는 인원도 안찼다고 해서 배구라도 하자고 마음먹 고 친구들도 데리고 왔어요."

하늘 : "전 환희가 여자배구 한다고 해서 같이 왔어요. 처음에는 코프볼이랑 고민하기도 했는데 우리 반 애들이 많이 가기에 배구로 왔죠." ( 2016.5 A그룹 1차 심층 면담 중 )

하니 : "전 처음에는 다른 스포츠클럽을 신청했는데 떨 어졌어요. 선생님이 대신 배구해보라고 권유했었는데 처 음엔 별로였어요. 배구는 사실 뭔지도 잘 몰라서 관심이 없었는데 친한 소민이가 같이 하자고 다음에 해보자고 마
음을 먹었죠."

소진 : "전 특별히 생각이 있지는 않았어요. 그런데 소 민이가 한다기에 같이 왔어요." ( 2016.5 B그룹 1차 심층 면담 중).

초등학교 6 학년 시기는 아동기와 청소년기 사이의 과 도기로서 2차 성징으로 이야기되는 급격한 신체적 변화 와, 감수성이 예민해지고 타인과의 관계를 중시하게 되 는 등 정신적으로도 급격히 성숙하는 시기이다. 특히 타 인과의 관계 중 또래 집단으로 이야기되는 교유관계는 이 시기의 가치관 형성과 정서발달에 큰 영향을 미치게 된다 (Shin, 2000).

이러한 측면을 통해 1 차 심층 면담 자료를 살펴보면, 스 포츠클럽 참여를 결정하는 데 영향을 끼치는 가장 큰 요 인은 바로 교우관계이다. 원하던 스포츠클럽 선발 시험 에서 떨어졌음에도 친한 친구의 권유에 전혀 관심이 없던 배구 종목을 선택하게 되었다는 하니의 면담 내용에서 이 를 단적으로 볼 수 있다.

"환희 덕분에 여학생들이 순식간에 많이 모여서 어느 덧 20 명을 채웠다. 체육관에서 시작한 첫 훈련, 좁은 체육 관에서 20 명에 게 배구를 가르치는 것은 생각보다 버거웠 다. 무엇보다 같은 반끼리 모여 있는 정도가 심했다. 환희 중심의 1 반, 소민이 중심의 2 반, 다연이 중심의 6 반까지 $\cdots$ 여자애들만 모아놓은 여자배구팀, 서로 친해져야 팀워크 가 맞을 텐데 조금 걱정스럽다." ( 2016.4 첫 훈련 후 지도 일지 중)

한편, 이러한 교우 관계 중심의 참여는 배구와 같은 단 체 종목에서의 팀워크를 형성하는 데 단점으로 작용할 수 있다. 여자배구팀 학생들이 3개 반에 집중되어 있고, 세 그룹 간의 상호작용이 원활하지 않고 마찰로 번지기까지 한다면 스포츠클럽 초기 정착기에 장애가 될 수 있기 때 문이다. 그러나체육활동은 학생들 간의 관계를 원만하게 해주며, 협동심과 일체감을 형성해주는 역할을 한다(You $\& \mathrm{Kim}, 2008)$. 교우 관계 중심의 참여를 긍정적인 분위기 로 이어나가기 위해서는 상호 관계를 증진과 협동심, 팀 워크와 같은 일체감을 형성시켜줄 수 있는 활동 분위기를 만들어 가야할 교사의 역량이 중요할 것이다.

연구자 : "지선이랑 진선이는 여자배구팀에 어떻게 들 
어오게 되었니?"

지선 : "배구가 재미있어 보였어요. 작년까지는 수영을 하면서 대회도 나갔었는데 올해 그만두게 되어서 운동이 하고 싶었거든요. 여자배구라기에 여자끼리만 하니까 재 미있을 것 같아서 가입했죠."

진선 : "친구 따라서 왔다가 보다는 그냥 하고 싶어서 왔어요."

연구자 : "배구라고 하고 싶었던 부분이 있었니?"

진선 : "아니요, 배구라서가 아니고 그냥 운동 할 수 있 다고 다음에 왔어요. 태권도도 지금 하고 있고, 운동은 할 수 있으면 해야겠다고 생각했거든요." (2016.5 A그룹 1차 심층 면담 중 )

대다수의 초등학교 여학생이 스포츠클럽 참여 동기에 있어서 교우 관계를 많이 이야기하지만, 순수하게 신체 활동에 대한 욕구로 참여하게 된 경우도 볼 수 있었다. 위 에서 제시한 두 연구 참여자의 공통점은 여자배구팀에 들 어오기 전 다른 형태의 신체 활동을 오랜 기간 동안 꾸준 히 해왔다는 점이다.

이러한 참여 동기를 가진 여학생들에 게는 교우 관계보 다는 운동 기능 향상 측면에서 지도하는 쪽이 더 효과적 일 것이다. 흔히 구기 종목으로 대표되는 전통적인 스포 츠에서는, 신체 능력과 운동 기능 면에서 뒤처지는 여학 생의 참여도가 남학생에 비해 낮고 소외되는 경향(Kim \& Cho, 2006)이 있는데 신체 능력과 운동 기능이 뛰어난 여 학생의 경우 관계 중심의 스포츠클럽 분위기보다는 실력 향상의 기능적 측면에 주목하는 쪽이 참여도를 높일 수 있는 방법일 것이다.

배구가 좋아지기 시작해요 연구자 : "4월 달에, 다들 서로 어색할 때 첫 연습을 시작하게 되었지. 첫 날에는 내가 리 시브하는 자세, 서브하는 자세를 알려주고 2명씩 공을 서 로 던져주며 리시브 연습을 했었는데 기억나니?"

하늘 : "처음엔 아팠어요, 손목에 멍도 들고 막..."

지선 : "맞아요, 멍도 들긴 했는데 재미있었어요. 처음 해봐서 그랬는지 몰라도 서브하는 것도, 리시브 받고 하 는 그런 게 다 재미있었어요."

하늘 : "맞아요, 배우다 보니까 일주일에 두 번 하는 연 습시간이 부족했어요. 더 많았으면 좋겠다고 생각했어 요."

진선 : "아프긴 했는데 배구 자체가 재미있었고, 학교
수업 끝나고 운동할 수 있다는 게 가장 중요했어요. 평소 에 학교에서 운동하는 시간이 부족했다고 느꼈거든요." ( 2016.5 A그룹 1차 심층 면담 중 )

하니 :"처음이라서 그런지 공에 맞을 때 아팠어요. 그런 데 자세를 배우고 연습이 되면서 가끔 공이 잘 맞아서 올 라가면 안 아프더라고요. 공을 팔에 잘 맞춰서 예쁘게 올 라가는 걸 볼 때 기분이 좋았어요." ( 2016. 5 B그룹 1차 심 층 면담 중 )

교우 관계가 스포츠클럽 참여 요인에 있어서 큰 부분 을 차지한다고 해도, 지속적인 참여를 만들어주는 건 스 포츠 활동 본연의 즐거움이며, 그 즐거움의 상당 부분은 새로운 것을 배워가면서 스스로 느끼는 운동능력의 향상 에 해당할 것이다. Yeo et al(2003)의 연구에서는 학생들이 새로운 기술을 습득하고, 해보지 못했던 운동을 할 수 있 는 기회가 주어졌을 때 스포츠 활동의 즐거움을 느낀다 고 하였다. 연구 참여자들 또한 여자배구팀 훈련을 시작 하면서 해보지 못한 배구라는 운동을 알게 되고, 배구에 필요한 운동 기능들의 기초를 익혀 가면서 스포츠 본연 의 즐거움을 느끼기 시작한 것이다. 학생들은 배구를 통 해 학교생활에 만족을 느꼈고, 이는 학교생활 뿐 아니라 수업에도 이어져 보다 나은 성취수준과 내적동기를 보여 줄 것이라고 기대할 수 있다(Lesque, Zuenhlke, Stanek, \& Ryan, 2004).

특히 몇몇 연구 참여자가 언급한 "운동할 수 있는 시간 이 주어지는 점이 만족스럽다"는 부분은 여러 의미를 가 지고 있다. 한편으로는 초등학교 학생들의 부족한 신체 활동 시간을 의미하지만 수업 시간 외에 운동할 수 있다 는 사실 자체가 학생들의 참여 동기가 된다는 점이다. 사 실 여학생들이 남학생들에 비해 체육수업을 선호하지 않 는 경향이 있지만, 체육 수업을 통한 신체 활동의 가치는 대다수가 인식하고 있다. $\operatorname{Lim}(2006)$ 의 연구에서도 나타나 듯이, 초등학교 여학생들의 $79 \%$ 가 체육 수업이 체력을 증 진하고 건강을 향상시키는 데 도움이 된다고 인식하고 있 다. 남학생들에 비해 표면적으로 드러나는 부분은 작지 만, 여학생들도 신체 활동 자체에 관한 필요성을 느끼고 있고, 이러한 인식을 스포츠클럽 활동을 통해 재확인하는 것이 참여도를 높일 수 있는 방안이 될 것이다.

연구자 : "너희들 포지션에 이제는 잘 이해하고 있지? 
하늘 : "세터 자리가 너무 좋아요. 처음에 연습할 때는 네트를 바로 마주해야 해서 부담감도 있었지만 $\cdots$ 이번 올 림픽 때 이효희 선수도 유심히 봈었어요."

지선 : "나는 김연경, 원래 TV에 배구 나오면 안 봤었는 데 이번엔 거의 다 봤어."

환희 : "저도 이모부가 체육 쪽에 관심이 많으신데, 이 번 올림픽 배구 경기 보면서 이모부에게 질문도 하게 되 고 관심이 많아졌어요."( 2016.7 A그룹 3차 심층 면담 중)

하나로 수업 모형으로 대표되는 체육에서의 간접 경험의 효과는 이미 많은 연구에서 입증되었다. Lee \& $\operatorname{Park}$ (2012)의 연구에서는 신체 활동이 아닌 글 읽기, 글쓰 기와 같은 서사적인 활동조차 체육에 접목되면 여학생들 의 체육에 대한 인식과 참여태도 변화에 긍정적인 영향을 준다고 이야기하고 있다. 스포츠에 대한 간접 경험이 해 당 스포츠 활동에 긍정적인 영향을 미치는 만큼 반대의 경우도 당연히 성립된다.

스포츠 활동을 시작하면서 그와 관련된 간접 경험에 도 관심을 가지고 되고, 그러한 관심이 다시 활동 참여에 긍 정적인 영향을 미치는 선순환 구조가 되는 것이다. 여자 배구팀 활동 기간 동안 이슈가 되었던 대한민국 여자배구 대표팀의 활약은, 배구에 이제 막 익숙해진 초등학교 여 학생들의 참여 요인에 도움이 된 것이다. 이러한 간접 경 험의 활용 또한 여학생의 신체활동 참여도를 높일 수 있 는 유용한 도구가 될 것이다.

떨리고 두렵지만 이기고 싶어요 "학교스포츠클럽 여자 배구리그 시합 첫 날, 굉장히 먼 거리의 학교들과 대결하 게 되었는데 우리는 연습 시작한지 이제 막 3 주가 지났을 뿐이다. 서브라도 잘 해주면 좋겠는데 연습량이 부족할 것 같아서 걱정이 된다. 상대 학교들은 작년부터 했던 아 이들도 있다는 데 $\cdots$ 아니나 다를까, 일방적인 경기 양상이 벌어졌다. 긴장한 나머지 얼어붙은 우리 팀 아이들은 실 수를 남발했고, 리시브 하나 제대로 올라오는 것도 보기 어려웠다. 다행히 지선이가 서브 실수 없이 침착하게 넣 어준 덕분에 행운초에게 한 세트를 딸 수 있었다. 돌아가 는 버스에서 너무도 아쉽다며 다음 주 부터는 아침에도 날을 잡아서 하자고 한다. 일찍 출근해서 가르칠 생각을 하니 피곤하기도 하지만 먼저 나서서 운동하자고 하는 녀 석들이 대견하다."( 2016.4 첫 리그 경기날 지도 일지 중)
연구 참여자들의 학교스포츠클럽 여자배구리그가 시 작되었다. 첫 예선 시합부터 2패로 모두 졌지만, 한 세트 를 이겼다는 사실에 연구 참여자들을 비롯한 여자배구팀 학생들은 매우 기뻐하였다. 기록상 2패이지만, 유일하게 획득한 한 세트가 일종의 성공 경험이었던 것이다. 스포 츠에서의 성공 경험은 참여에 관련된 내적 동기를 긍정 적으로 발현시켜 자발적이고 지속적인 참여를 유도한다 (Lim et al. 2011). 비록 그것이 일시적인 감정 흐름에서 나 온 움직임일지라도, 자발적으로 나서서 운동 시간을 추가 하자는 여자배구팀 학생들의 태도는 단순히 교우 관계로 시작한 스포츠클럽 활동도 얼마든지 학생들의 자발적인 참여로 이어질 수 있다는 것을 보여준다.

연구자 : "4월 말 첫 리그 시합 기억하니? 너희들 배구 시작한 지 채 한 달도 안되었는데 첫 리그 일정이 잡혔지. 시합 전날에 포지션 정한다고 아침에 불러서 서브 테스 트하고..."

하늘 : "와, 그때 정말 잘하고 싶었어요. 내일 시합이라 는 생각에 막 떨리기도 하고 $\cdots "$

환희 : "전 제가 많이 부족했다는 걸 느꼈어요. 내 차례 가 왔는데도 자신이 없어서 뒤에 있던 애한테 먼저 하라 고 했었거든요."

지선 : "저도 잘 넣고 싶은 기억밖에 안나요. 왠지 여기 서 못하면 내일 시합에서도 실수할 것 같았어요."

연구자 : "그렇게 서브 테스트를 해서 A팀, B팀을 나눠 서 다음 날 시합을 했었지. 우리가 딱 한 세트만 이기고 나 머지 세트는 다 졌었는데, 그때 시합했던 느낌이 어땠니? 환희 : 굉장히 진지했던 기억이 나요. 평소 체육시간엔 옆 에 애들하고 장난치기도 했는데 그러면 안 될 것 같은 분 위기라 떨리기도 하고.." (2016.6 A그룹 2차 심층 면담 중)

그러나 모든 연구 참여자들이 시합을 통해 성공 경험만 을 얻는 것은 아니다. $\operatorname{Kim}(1999)$ 은 여자 선수들이 남자 선 수들에 비해 실패에 관하여 더 큰 스트레스를 겪는다고 하였다. 내가 실수할 것만 같은 두려움, 익숙하지 않은 시 합 분위기에서 오는 긴장감은 성공 경험이라는 빛 뒤에 숨어 있는 그림자이다. 특히 다른 학생들에 비해 기능 향 상이 느렸던 환희의 경우 시합을 준비하는 과정부터 상당 한 부담을 가지고 있었고, 이러한 부담감은 경기에서의 실패와 만날 경우 더욱 더 자신감을 하락시키고 활동 참 여를 저하시킨다. 


\section{스포츠클럽 참여 요인}

여학생들만의 아지트 스포츠 활동에 참여를 높이는 중요 한 요인에는 신체 능력 개발도 있지만, 스포츠 내에서 사 회적 관계를 형성하고 그를 통해 얻는 즐거움과 기쁨도 빼놓을 수 없다(Weiss, 2000). 이와 관련하여 여학생 스포 츠클럽의 참여 요인 중 큰 비중을 차지하는 것은 여학생 들끼리 모여서 한다는 점이다. 위에서 언급했던 가입 동 기에 관한 질문에 '여자끼리만 한다기에 재미있을 것 같 아서 왔다' 라는 지선이의 응답은 여학생끼리 모여서 운 동한다는 사실이 운동에 대한 흥미 못지않은 여학생 스포 츠클럽의 중요한 참여 요인이라는 점을 보여준다. 한편, 이렇게 여학생들만 모여서 하는 점에서 여학생 스포츠클 럽의 부정적인 면도 존재할 수 있다. 후속 연구로 여학생 스포츠클럽의 한계와 보완점을 다뤄보는 것도 의미 있는 발걸음이 될 것이다.

6.28 (화) : 환희가 탈퇴 의사를 전달, 같은 반의 $\mathrm{OO}$ 가 멋대 로 하는 것이 불쾌하다고 함.

7.5(화) : 남자애들이 싫어서 코프볼 팀을 탈퇴했던 소현이 가 여자배구팀에 가입을 신청하여 연습 참여

7.9(금) : 1 학기 때 몇 번의 권유에도 가입하지 않았던 진선 이가 은채와 함께 여자배구팀에 가입을 신청하여 첫 연 습 참여

9.6(화) : 개학 후 소현이와 친한 유빈 추가 가입, 환희 복 귀. 하교 후 화장을 한 후 훈련에 참여하는 학생들이 많아 짐(소현, 유빈)

9.20(화) : 진선을 비롯한 몇 명이 연습이 끝나고 체육관에 서 더 있어도 되냐고 물어 17:30까지 시간 보내도 된다고 허락함. (2016.6 9 관찰 일지 중)

위에서 제시한 관찰 일지 중 주목할 부분은 스포츠클 럽(코프볼팀)을 탈퇴했던 소현이의 여자배구팀 재가입 이다. 연구자는 여자배구팀과 함께 혼성 스포츠클럽인 코 프볼팀도 동시에 지도하고 있었는데, 운동 능력도 평균 이상이었고 교우 관계도 원만한 소현이의 코프볼팀 탈퇴 원인은 다름 아닌 남학생들의 존재였다. 나의 운동하는 모습을 드러내기 싫고 비난받기 싫었지만, 신체 활동 참 여 욕구를 가지고 있던 소현이는 여학생 스포츠클럽인 여 자배구팀에 가입을 신청하게 된 것이다. Kwon et al(2012) 의 여중생의 학교스포츠클럽 문화 탐색에 관한 연구에서, 학교스포츠클럽은 여학생들의 관계를 확장시킬 수 있는
정보 교환의 장이자, 수다가 있는 그들만의 아지트라고 이야기하였다. 운동이 끝나고도 남아서 함께 놀고, 서로 화장법을 공유하는 등 여학생 스포츠클럽은 체육수업에 서는 찾을 수 없는 그들만의 아지트가 된 것이다.

연구자 : 이번 달부터 남학생들이 와서 연습을 도와주게 되었는데 어땠었니?

선영 : 전 일단 싫었어요. 음, 많이 싫었어요. 일단 눈치를 보게 되잖아요.

하니 : 저도 싫었어요, 하면서 뭔가 눈에 거슬린 다랄까 $\cdots$ (2016.9 B그룹 3차 심층 면담 중)

그런데 이러한 그들의 아지트에 변화가 생긴 건 7월부 터였다. 간이배구리그 경험을 통해 배구에 관심을 보이던 남학생들을 보조 역할로써 여자배구팀 선수들의 훈련을 돕게 한 것이다. '싫어요' , '눈에 거슬려요' 라는 강 한 어조의 부정 표현에서 나타나듯 자신들의 운동 장소 에 나타난 남학생들의 존재는 이유 여하를 불문하고 불 호(不好)의 영역이었다. 여자배구팀이라는 이름만큼, 자 신과 같은 성별의 친구들이 모여 있다는 점은 여학생들은 매우 중시하였다.

1 학기 말부터 체육수업으로 했었던 6학년 간이배구리그 로 남학생들의 배구에 대한 관심이 급증했다. 여자배구팀 훈련에 같이 참여하고 싶다는 이야기부터, 왜 여자애들 만 배구스포츠클럽이 있냐면서 부당함을 호소하는 이야 기까지 각양각색이었다. 여자배구리그 경기 일정도 모두 끝났고, 목표가사라져서 그런지 일부 여자배구팀 학생들 은 배구를 배우러 오기보다는 자기들끼리 놀려고 오는 듯 한 인상을 풍겼다. 참여하고 싶은 남학생들을 몇 명 불러 서 훈련도 돕게 하고, 연습 경기 상대 역할을 맡기면 새로 운 동기 부여 요인이 될 것 같아서 남학생들을 부르기 시 작했다. 일단 두드러진 건 부정적인 효과였다. 여학생들 로부터 '개들 왜 불러요' 라는 목소리가 나오기 시작했 고, 당장 훈련을 빠지는 학생들도 많아졌다.

(2016.9 지도 일지 중)

남학생들의 협력적 참여 여학생들끼리 모여서 활동한다는 것을 바꾸어 말하자면 남학생들의 부재(不在)라고 할 수 있다. 연구 참여자들은 이 점이, 자신들의 신체 활동 정도 를 결정하는 아주 중요한 것이라고 공통적으로 이야기한 
다.

연구자 : 남자애들이 있으면 할 수 있다는 게 적어진다는 게 무슨 뜻이니?

선영 : 남자애들이 역할을 독점하니까요.

하니 : 맞아요, 남자애들이 우리가 하는 것까지 빼앗아서 해요.

연구자 : 그래도 연습을 도와주면서 너희들에 편해진 부 분도 있는데, 어느 부분이 싫은 거니?

선영 : 어디가 싫다기보단, 같이 있으면 말도 적어지고 그 낭 불편한 것 같아요.

소진 : 부담스러워졌어요. 스스로 위축된다는 느낌...

(2016.9 B그룹 3차 심층 면담 중)

‘독점’ 이라고 표현한 여학생들의 불만은 대부분 체육 수업에서의 경험에서 기인한다. Kim et al(2008)의 연구에 서는, 근대스포츠에 남녀가 함께 참여하는 경우 신체적 능력이 떨어지는 사람들이 소외되는 경우가 많고, 특히 여성이 그러한 소외계층에 해당하는 경우가 많다고 이야 기한다. 이는 비단 학생의 경우에만 해당하지 않고 성인 의 경우에도 해당되는데(Yu \& Lee, 2006) 기능 중심 체육 수업이 이러한 인식을 심화시킨다고 할 수 있다.

그러나 다행히도, 이러한 남학생들의 동참(同參)에 부정 적인 측면만 있는 것은 아니었다. 훈련이 원활하게 이루 어질 수 있도록 도와주는 것에 대해 긍정적으로 생각하 는 한편, 격어보지 못한 새로운 상대와 연습 시합을 함으 로써 새로운 동기 부여의 에너지를 얻는 경우도 있었다.

연구자 : 요즘 남자애들이 해주는 보조 역할에 대해 어떻 게 생각하니?

환희 : 공을 대신 주워주니까 연습 진행도 빠르고 몸도 덜 피곤해요.

진선 : 남자애들과 연습 시합을 하는 게 우리끼리 할 때보 다 진행도 빠르고 재미있어요. 우리끼리 하면 서브가 안 넘어오는 경우가 많아서 종종 지루하거든요.

지선 : 스파이크 연습도 더 재미있어요. 남자애들이 블로 킹을 하는데, 개네들 블로킹을 넘겨서 공이 코트에 들어 가는 게 뭔가, 굉장히 기분 좋다랄까...

진선 : 맞아요, 우리끼리 연습할 때는 몰랐는데 남자애들 블로킹이 생기니까 그걸 넘겨야겠다는 의지 같은 게 생 겼어요.

(2016.9 A그룹 3차 심층 면담 중)
비난 없는 활동 시간 하지만 남학생들의 훈련 보조 역할 을 긍정적으로 생각하는 연구 참여자들조차 다 같이 부 정적으로 보는 측면이 있는데 바로 비난이다. 비난은 초 등학교 여학생들이 체육수업을 싫어하게 되는 주요 원인 중의 하나로, 특히 경기에서 실수를 하였을 때 쏟아지는 남학생들의 비난과 힐책이 창피하고 두렵다는 연구 결과 (Yang, 2003)가 이를 잘 보여준다.

하니 : 평소에 우리한테 뭐라 하는 것처럼 여자배구 훈련 에서도 저희한테 뭐라고 할까봐, 그게 제일 걱정되었어 요.

선영 : 맞아요, 평소에도 같은 친구끼리인 데 개들은 체육 시간마다 빨리 가서 잡아라, 제대로 해라라며 명령조로 이야기해요.

하니 : 체육 시간에 간이배구 시합 할 때도 저한테 '여자 배구부 주장이면서 그것밖에 못하냐’ 라고 했어요.

( 2016.9 B그룹 3차 심층 면담 중 )

일반적으로 여학생들은 남학생들보다 친밀감과 감성 수 용, 돌봄, 신뢰, 즐거움 측면을 더 중시하고 자신에 대한 정 서적 지지와 정보를 제공하는 친구와의 관계를 유지하기 위해 더 노력하는 편이다(Kwon, 2006).

한편, 이러한 남학생들의 비난에는 자신보다 신체조건이 낮은 여학생들을 약자로 보기 때문인 측면도 있지만 승부 욕의 측면도 존재한다. $\operatorname{Kim}(2007)$ 은 소꿉놀이로 대표되 는 여성의 놀이는 타인과의 조화를 중시하는 반면, 구슬 치기나 딱지치기와 같은 남성의 놀이는 승부욕을 중시하 면서 이러한 문화의 차이가 남녀의 승부욕 차이에 영향을 끼쳤다고 하였는데, 연구 참여자 중 한 명도 이러한 남녀 의 승부욕차이에 대해 인식하고 있었다.

선영 : 점수 세는 걸 실수한 것뿐인데 진짜 눈물이 많이 났 어요. 저한테 눈이 삐었냐면서, 욕을 하는데 아니 그깟 연 습 경기가 뭐 그리 중요하다고 $\cdots$

연구자 : 그랬구나, 개들이 많이 예민했었나보구나. 승부 옥이 강하니까 개들이 $\cdots$

선영 : 그렇게까지 남에게 상처 주는 건 아닌 것 같아요. 그때 이후로 훈련에 나오기 싫어서 계속 빠진 거였어요. ( 2016.9 선영이와의 심층 면담 중) 


\section{체육수업 참여 활성화 사례}

스포츠클럽 활동을 체육수업과 연계하여 긍정적인 경 험을 확장시키는 것은 매우 중요하다(Light \& Curry, 2008). 참여 요인에서 보이는 것처럼 초등학교 여학생들이 체육 수업에서 원하는 것은 남녀 간의 협력적 참여를 바탕으로 한 비난이 최소화된 수업이다. 아울러 단순히 교사 위주의 기능중심 수업이 아닌 학생의 참여를 중시하는 수업으로 친구들 간의 관계도 함께 증진할 수 있는 아지트 역할까지 할 수 있는 수업을 원하고 있다.

이러한 부분을 고려하여 스포츠클럽 활동을 체육수업 과 연계하기 위해서는 기능이 뛰어나지 않거나 신체활동 을 선호하지 않는 학생까지 수업에 참여시킬 수 역할을 부 여하고, 적절하게 팀을 구성하여 각자 자신의 팀 내에서 역할을 수행하며 동료와의 관계를 증진할 수 있는 수업이 설계되어야 하는데 그동안 스포츠 교육 모형이 이러한 수 업 설계에 적합하게 여겨져 다양한 연구들이 진행되어 왔 다(Moon, 2000; Kim, 2003; Choi \& Kim, 2009; Park, 2013).

특히 연구자는 운동기능이 낮은 여학생의 스포츠교육 모형 참여에 관한 연구(Choi, 2004)에 주목하여 변형 게임 으로 시즌을 운영하고, 다양한 역할 부여를 통해 승패 위 주에서 협력과 사회성 발달 목표로 하는 수업을 다음과 같 이 구안하여 실천하였다. 추후 여기에서 다루지 못한 건 강, 도전, 표현 활동에서 스포츠클럽과 연계한 체육수업 참여 활성화 방안이 다룰 수 있을 것이다.

\begin{tabular}{|c|l|}
\hline \multicolumn{2}{|c|}{ Table 3. Simple-Volleyball Lesson Plan } \\
\hline $1^{\text {st }}$ & $\begin{array}{l}\text { - Introduce Volleyball Rule } \\
\text { - Introduce Simple-Volleyball Rule }\end{array}$ \\
\hline $2^{\text {nd }}$ & $\begin{array}{l}\text { - Build teams - 2 boys team, } 2 \text { girls team } \\
\text { - Simple-Volleyball Serve Training }\end{array}$ \\
\hline $3^{\text {td }}$ & $\begin{array}{l}\text { - Simple-Volleyball Receive Training } \\
\text { - Team Circuit Training - Serve, Receive }\end{array}$ \\
\hline $4^{\text {th }}$ & $\begin{array}{l}\text { - Simple-Volleyball Toss Training } \\
\text { - Team Circuit Training - Receive, Toss }\end{array}$ \\
\hline $5^{\text {th }}$ & $\begin{array}{l}\text { - Simple-Volleyball Spike training } \\
\text { - Team Circuit Training - Receive, Spike }\end{array}$ \\
\hline $6^{\text {th }}$ & $\begin{array}{l}\text { - Preparation for Simple-Volleyball League } \\
\text { - Build a Team Entry for League }\end{array}$ \\
\hline $7-13^{\text {th }}$ & $\begin{array}{l}\text { - Simple-Volleyball League } \\
\text { - Explore Strategies after each match }\end{array}$ \\
\hline $14-15^{\text {th }}$ & $\begin{array}{l}\text { - Simple-Volleyball League Play-Off } \\
\text { - After-League Festival }\end{array}$ \\
\hline
\end{tabular}
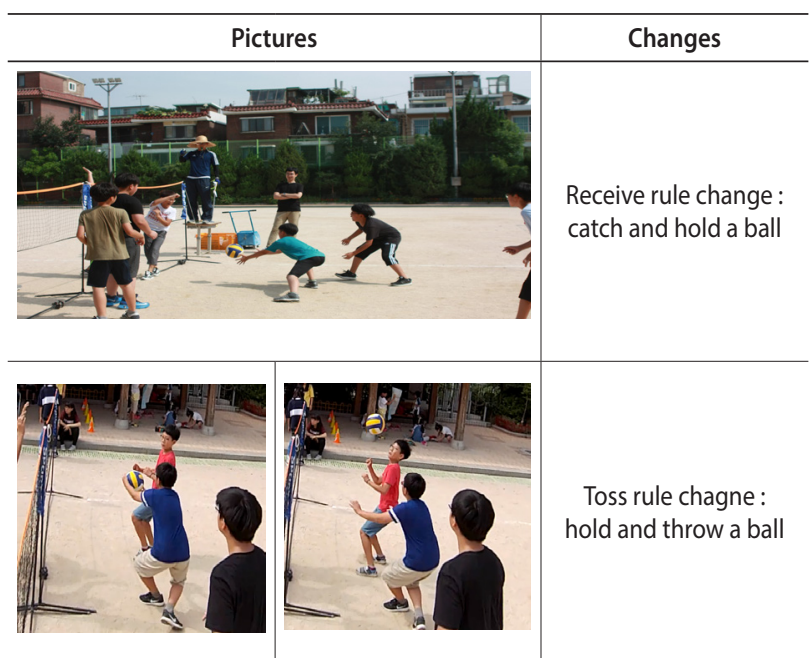

Toss rule chagne: hold and throw a ball

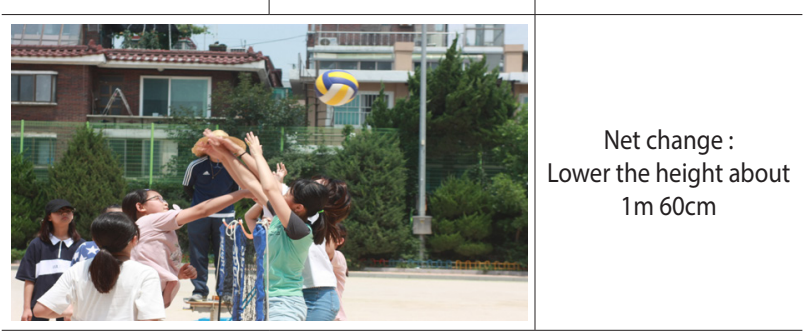

Figure 1. Simple-Volleyball Rule

\section{변형 게임(간이배구)과 스포츠 시즌 운영}

학생들에게 교육적으로 폭넓은 스포츠 경험을 제공하 기 위해 Sidentop(1994)이 계획한 모형인 스포츠교육모형 의 특징은 시즌 운영이다. 각 반의 학생들은 선수뿐만 아 니라 코치, 사진기사, 경기 기록원, 캐스터와 해설 등 다양 한 역할로 시즌에 참여하며, 이를 통해 스포츠인으로서의 소양을 기르는 것이 스포츠교육 모형의 목표이다. 초등학 교 학사 일정 과 수업 시수를 고려하여 <Table 3>과 같이 15 차시로 차시별 수업 계획을 구성하였다.

규칙 변형은 <Figure 1>와 같다. 배구의 리시브와 토스 는 높은 수준의 기능을 요하는 반면, 스파이크의 경우 네 트의 높이를 조절하면 초심자도 쉽게 따라할 수 있기 때문 에 리시브와 토스 기능을 변형하였다.

이러한 간이 배구로의 규칙 변형은 심동적 영역과 인지 적 측면에서 경기 관련 기능을 학습하는 데 주요한 효과를 보였다. 정식 배구의 리시브, 토스와 같은 기능들은 5 개월 넘는 기간 동안 스포츠클럽(여자배구팀)을 통해 배운 연 구 참여자들도 숙련도가 상당히 부족한 상태였다. 연구 참 여자들은 간이 배구 수업 초반에는 정식 배구 형태가 아니 라는 생각에 부정적인 반응을 보였으나, 쉬워진 기본 기능 
들 덕분에 경기 양상이 다양해진 측면에 만족하였고 배구 종목에 대한 이해도가 심화되었다.

연구자 : 1 학기 말부터 간이배구 시즌이 운영되었지. 처 음에는 어떤 생각이 들었니?

하늘 : 음, 처음에는 가짜배구라는 생각 밖에 안 들었어 요.

지선 : 전 스파이크를 훨씬 더 많이 할 수 있어서 좋았어 요. 솔직히 여자배구팀에서 저희끼리 연습을 하면 제 대로 스파이크를 할 일이 없었거든요. 그런 데 간이 배구는 리시 브와 토스가 쉬워지니까 안 해본 친구들도 조금만 연습하 면 바로 할 수 있어서 좋은 것 같아요.

진선 : 상대방이 스파이크를 많이 하게 되니까 배웠던 블로킹도 할 기회가 많이 생겼어요. 블로킹 잘하는 방법 도 팀 애들이랑 이야기하게 되고 더 재미있는 것 같아요.

(2016.9 A그룹 3차 심층 면담 중)

\section{학생 중심의 시즌 참여}

스포츠 활동에서 여전히 많이 쓰이고 있는 수업모형인 기능중심모형은 세분화된 기능의 반복 연습을 통해 실제 상황에서 그 기능들이 통합되는 것을 목적으로 하고 있다. 그러나 단편적인 상황에서 습득된 기능은 학생들이 실제 시합상황에서 적용하는 데 어려움을 겪는다는 비판도 크 다(Kim, 2016). 실제 상황에 적용할 수 있는 기능은 기능중 심모형이 아닌 스포츠교육 모형의 자율적 기능연습과 많 은 시합 경험을 통해 습득된다. 이를 위해 각 반별로 다른 7 개 반과 한 번씩 모두 경기를 치를 수 있도록 정규리그 일 정을 조정하였으며 팀 편성은 각 반 체육부장을 중심으로 하여 학생들과 협의를 거쳐 연구자에게 엔트리 표를 제출 하게 하였다. 남자 2 개 팀은 실력에 따라 $\mathrm{A}$ 팀과 $\mathrm{B}$ 팀으로 구성하게 하여, 학급 간 실력을 최대한 균등화하여 정규 리그가 진행될 수 있도록 하였다. 엔트리 표는 < Figure 2> 와 같다.

이러한 시즌 운영은 정의적 영역 측면에서 연구 참여 자들이 자율성을 가지고 수업에 참여하는데 도움을 주었 다. 스포츠 활동이 구성원들의 소속감을 증대(Eime, Payne \& Harvey, 2008)시키고, 그들 간의 관계와 응집력을 강화시 킨다(Townsend, Moore \& Mahoney, 2002). 학교스포츠클럽 (여자배구팀)에서 활동 경험이 있는 연구 참여자들은 각 반의 팀 편성과 전략수립에 있어서 주도적인 역할을 맡아 참여하였고, 경기 후에도 각 반의 팀 동료들과 함께 시합

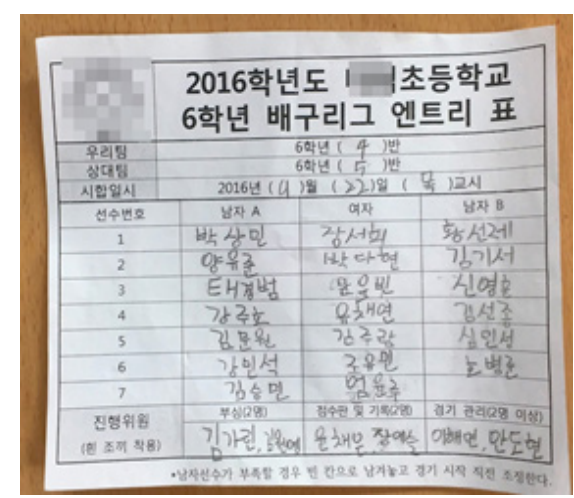

Figure 2. Simple-Volleyball League Team Entry

에 대해 활발하게 피드백을 주고받는 모습을 보였다.

연구자 : 1,3 반한테 아쉽게 졌구나 너희들.

하니 : 1 반은 지선이도 있고 잘하는 애들이 많아서 그러 려니 하는데 3 반한테 진 건 진짜 아쉬웠어요.

선영 : 맞아요, 진짜 이길 수 있었는데 $\cdots$ 저희 뭐가 부족 했던 거죠?

연구자 : 블로킹이 너무 약해서 키가 큰 3 반 공격수들에 게 득점을 너무 쉽게 내주고 있어.

하니 : 맞다, 저희 다솔이랑 은주랑 키도 크고 한데 블로 킹을 너무 뒤에서 했던 것 같아요. 남자애들도 비슷한 애 기를 했었어요.

선영 : 조세현이랑 개네들은 맨날 저희보고 이래라 저 래라 시키기만 해요.

하니 : 남자애들은 시합을 거의 이기고 있으니까, 우리 여자팀이 지는 게 답답한가봐.

(2016.9 B그룹 3차 심층 면담 중)

\section{모두가 함께하는 축제, 순위결정전}

정규리그 일정이 끝난 후 스포츠교육모형의 '축제' 요소에 착안하여 간이배구 시즌 순위결정전(Play-Off)을 진행하였다. 축제 요소를 강조하기 위해 정규리그 역할을 포함한 새로운 역할들(캐스터, 사진기자, 경기기록원)을 추가하였으며 남자부와 여자부 경기를 구분하여 각 경기 를 위해 남자 3 팀, 여자 3 팀을 구성하도록 하였다. 순위결 정전의 경기기록은 간이배구 시즌 개인별 시상을 가능하 게 하였고, 캐스터는 즐거움 요소를 확대하였으며 사진기 자가 촬영한 사진은 시상식에 활용되었다. 각 역할은 학생 
들이 자율적으로 할 수 있게 하였으며, 이러한 자율적 운 영은 학생들의 자신감 증가와 불안감 감소(Smith \& Smoll, 1997)에 영향을 미쳐 시즌에 참가한 구성원들의 즐거움을 확대할 수 있었다. 연구 참여자 또한 이러한 영향을 통해 간이배구 경기를 바라보는 시야기 넓어지게 되었는데, 처 음에는 자신의 운동 기능 향상과 경기에 이기기 위한 선수 로서의 역할에만 집중하던 연구 참여자도 점차 경기 기록 에 따른 개인 순위나 다른 친구들이 맡은 선수 외의 여러 역할에도 관심을 가지고 되면서, 선수 외적으로 활동을 바 라보는 시야를 갖추게 되었다.

연구자: "1위 축하한다, 여자배구팀 자존심을 지켰구 나."

지선 : "조금 아쉽긴 해요. 3 반 애들이 자기들끼리 무너 지는 바람에 스파이크 할 기회도 없었어요, 개인 기록도 잘 받고 싶었는데 $\cdots "$

연구자 : "그러게, 아마도 5반에 시하가 개인 기록은 제 일 잘 나올 것 같다."

지수:"정규리그 경기부터 경기 기록을 했으면 더 좋았 을 것 같아요. 하늘이도 그렇고 다들 기록에 관심을 많아 요."

지선 :"지수가 캐스터 한 거 완전 웃겼어요. 다른 애들도 재미있었대요, 그런데 이제 순위결정전까지 끝났다니 아 쉬워요." ( 2016.9 지선이와의 심층 면담 중)

\section{결론}

초등학교 여학생의 스포츠클럽 참여 모습은 시작 단계 에서 또래 친구에 대한 모방심리와 해당 운동에 대한 관 심이 나타나며 전개 단계에서는 지속적 참여를 통한 애착 과 시합에서의 승부욕, 실패에 대한 두려움 등이 나타났 다. 그리고 여학생 스포츠클럽 참여 요인은 아지트로 표 현되는 참여 학생들만의 공간 확보, 남학생들의 협력적 참 여 및 비난이 없는 활동 시간으로 드러났다. 이러한 부분 과 체육수업을 연계하여 스포츠 교육 모형을 바탕으로 한 간이배구 시즌 운영을 체육수업 활성화 사례로 제시한 결 과, 규칙 변경을 바탕으로 한 스포츠 시즌 운영, 학생 중심 의 참여, 순위결정전을 비롯한 축제 요소가 체육수업 활성 화 방안의 하나로 제시될 수 있을 것이다.

\section{Conflicts of Interest}

The authors declare no conflict of interest.

\section{References}

Bae, S. S., Kim, K. S., Won. Y. S., Cho. M. H., You, J. A. (2005). An analysis of females and males 'perception, experiences and needs toward elementary physical education classes. Korean Journal of Sport Pedagogy, 12(1): 115138.

Back, S. Y. (2012). Stress of Elementary School schoolgirl and About school lift adaptation research (master dissertation). Daeshin university, Kyungsan, Republic of Korea. Ministry of Education(2011). School sports club development plan. Seoul : MOE

Birgitta F, Hakan L. \&Karin, R. (2012). The game within the game: girls' underperforming position in physical education. Gender and Education, 24(1), 101-118.

Casey, M. M., Eime, R. M.., Payne W. R., \& Harvey, J. T. (2009). Using a socioecological approach to examine participation in sport and physical activity among rural adolescent girls. Qualitative Health Research, 19(7), 881-893.

Centers for Disease Control and Prevention (2002). Promoting better health for young people through physical activity and sports. Atlanta, GA: Centers for disease control and prevention.

Choi, W. J. (2004). An analysis of participation in physical education of low skilled girl on sport education. The Korean Journal of Physical Education, 43(5), 217-227.

Choi, H. S., \& Kim, M. S. (2009). A research on students' responsibility change through an integration of TPSR and the sports education model. Journal of Research in Curriculum Instruction, 13(4), 773-801.

Creswell, J. W. (2009) Research design: Qualitative, quantitative, and mixed methods approaches, Sage

Dwyer, J. J. M., Allison, K. R., Goldenberg, E. R., Fein, A. J., Yoshida, K. K. \& Boutilier, M. A.(2006). Adolescent girls' perceived barriers to particiation in physical activity. Adolescence, 41, 75-89.

Eime, R. M., Payne, W. R., \& Harvey, J. T. (2008). Making sport- 
ing clubs healthy and welcoming environments: a strategy to increase participation. Journal of Science and Medicine in Sport, 11, 146-154.

Greendorfer, S. L. (1992). Sports socialization In T. S. Horn (Ed), Advances in sport psychology(pp. 201-218). Champaign: IL, England: Human Kinetics.

Je, J. H., \& Yu, H. K. (2013). The development of a group counseling program through play therapy to prevent bullying of higher grade elementary school girls. The Journal of Korean Sociery for Child Education, 22(1), 285-300.

Kang, J. W. (2016). Differences in social development and satisfaction of school life according girl students' participation in middle school sports league to. (Master dissertation). Inha university, Incheon, Republic of Korea.

Kim, B. J. (1999). Sources of enjoyment and stress in sports among Korean young athletes. Korean Journal of Sport Psychology, 10(2), 193-209.

Kim, J. R. (2007). How to raise your daughter as a strong girl. Book 21

Kim, J. Y., \& Kim, J. W. (2017). Changes in physical education perceptions and attitudes according to participation experience in elementary school girl-led sports club. Korean Alliance for Health, Physical Education, Recreation, and Dance, 56(6), 31-41.

Kim, K. Y. (2016). A case study on the effects of sports education curriculum model using volleyball (master dissertation). Andong university, Andong, Republic of Korea.

Kim, M. Y., \& Cho, M. H. (2006). The experience sport education and gender equality by female students. Korean Journal of Sport Pedagogy, 13(4), 145-161.

Kim, M. H., \& Lee, G. I. (2008). An action research to improve girls' participation in physical education. The Korean Journal of Physical Education, 47(6), 303-313.

Kim, W. J. (2017). A study on the activating for physical education and sport by analyzing research trends on the Korean girls' physical activity. Journal of Korean Association of Physical Education and Sport for Girls and Women, 31(3), 73-93.

Kim, Y. H. (2003). Qualitative analysis on experiences of lowskilled students in physical education. Korean Journal of Sport Pedagogy, 10(1), 57-76.
Kim, Y. C. (2012). Qualitative inquiry \& research design1(Bricoleur). Academy Press

Kwon, H. J. (2006). Early adolescents' friendship maintenance strategies and satisfaction with their best friends (Master dissertation). Yonsei university, Seoul, Republic of Korea.

Kwon, H. I., Kwon, Min. Jung., \& Son, H. (2012). Exploration into club culture of a female middle school students participating in school sports club activity. The Korea journal of sports science, 21(6), 993-1006.

Lee, J. M., \& Park, J. J. (2012). Exploring the high school girls' perceptions on and participation attitudes of PE class through an integrated narrative PE activities (Master dissertation). Seoul national university, Seoul, Republic of Korea.

Lee, J. S., \& Choi, Y. S. (2001). An ethnographic study on bullying behavior problems in elementary school. The journal of Elementary Education, 14(2), 181-211.

Lesque, C., Zuehlke, A. N., Stanek, L. R., \& Ryan, R. M. (2004). Autonomy and competence in German and American university students: A comparative study vased on self-determination theory. Journal of Educational Psychology, 96, 68-84.

Light, R., \& Curry, C. (2008). Children's reasons for joining sport clubs and staying in them: a case study of a sydney soccer club. ACHPER Healthy Lifestyles Journal, 56(1), 23-27.

Lim, D. S.(2006). Analysis of female student attitudes toward physical education in elementary school (Master dissertation). Korea national sport university, Seoul, Republic of Korea.

Ministry of Culture, sports and Tourism. (2011). 2011 National health status survey. Ministry of Culture, Sports and Tourism.

Ministry of Education(2007). A study on the development plan of school sports club operation. Seoul : MOE

Moon, H. J. (2000). A case study of sport education curriculum model in teaching physical education at a selected secondary school. Korean Journal of Sport Pedagogy, 7(1): 1-19.

Oh, J. K. (2015). Participation experiences and challenges of 
female netball school sports club at middle schools. Journal of research in curriculum instruction, 19(4), 897-921.

Park, J. M. (2013). The effects of sport education model applied to the "Sireum class on students" attitude toward physical education, psychological aspects and social aspects. Journal of Sport Science, 25:15-31.

Portman, P. (1992). The experience of low-skilled students in public school physical education: The significance of being chosen last. (Unpublished doctoral dissertation), University of Massachusetts, Amherst, United States.

Robert, A. M., Steven, G. E. (2002). A history and philosophy of sport and physical education: from ancient civilizations to the modern world. McGraw-Hill College. Bang-chul Kim (ed.)(2005). A history and philosophy of sport. Seoul: Rainbow-books.

Seoul Metropolitan Office of Education(2016). 2016 Seoul metropolitan office of education school sports club convention operation plan. Seoul : SMOE

Shen, B., Rinehart-Lee, McCaughtry, N. \& Li X.(2012). Urban African-American girls' participation and future intentions toward physical education. Sex roles, 67(5), 323333.

Shin, J. E. (2000). The relations between friendship, peer aggression and victimization by peers in early adolescents. Journal of Korean Home Management Association, 18(1):153-165.

Shin, J. S. (2000). An ethnographic study on the conflict within class in elementary school (Master dissertation). Korean national university of edcuation, Cheong-ju, Republic of Korea.

Sidentop, D. (1994). Sport education: Quality PC through positive sport experience(pp.61-72). champaign, IL: Human kinetics.

Simth, R. E., \& Smoll, F. L. (1997). Coaching the coaches: Youth sports as a scientific and applied behavioral setting. Current Directions in Psychological Science, 6(1), 1621.

Taylor, J., Hughes, A. \& Koufaki, P. (2013). The impact of community-based physical activity projects on girls' and young women's engagement in physical activity: find- ings from an evaluation of the 'Girls on the move' programme. Managine leisure, 18(1), 46-60.

Townsend, M., Moore, J., \& Mahoney, M. (2002). Playing their part: the role of physical activity and sport in sustaining the health and well-being of small rural communities. The International Journal of Rural and Remote Health Research, Education, Practice and Policy, 2(109), 1-7.

Walling, M. D., \& Martinek, T. J. (1995). Learned helplessness: A case study of a middle school student. Journal of Teaching in Physical Education, 14(4), 454-466.

Weiss, M. R. (2000). Motivating kids in physical activity. President's Council on Physical Fitness and Sports Research Digest, 3(11), 1-8.

Williams, L., \& Gill, D. L. (1995). The role of perceived competence in the motivation of physical activity. Journal of Sport \& Exercise Psychology, 17(4), 363-378.

Yang, G. R. (2003). An analysis on the females student alienation factors in physical education classes of elementary school. Journal of Korean Society for the Study of Physical Education, 8(1), 73-92.

Yeo, J. K., Lee, C. S., \& Nam, S. W. (2005). An analysis of enjoyment factors of physical education class in elementary school, Korean Journal of Physical Education, 21(1), 38-49.

Yi, K. H. (1998). A study on brassiere wearing by elementary school girls. Journal of Korean Association of Human Ecology, 7(1), 147-165.

You, S. Y., \& Kim, K. S. (2008). Children's perception and awareness of elementary school physical education. Journal of Coaching Development, 10(3), 23-43.

Yoo, B. S. (2003). Effects of peer relation improvement program on the self-esteem of 4 th graders (Master dissertation). Incheon national university, Incheon, Republic of Korea.

Yoo, S. S. (2004). Strategies to enhance girl's positive attitude toward physical activity. Korea Sport Research, 15(6), 1525-1538.

Youn, H. S.(2013). A narrative inquiry on what a middle school girl student who was once "Wangtta" at school gained while she worked as a manager of the school baseball club. Korean Journal of Sport Pedagogy, 20(2): 159-176. 
Yu, T. H., \& Lee, B. J. (2006). Exploring the concept of new sports and its educational meaning. Korean journal of Sport Pedagogy, 13(1), 67-82. 